\title{
Impact of High Light on Reactive Oxygen Species Production within Photosynthetic Biological Membranes
}

\author{
Vetoshkina D. V. \\ Institute of Basic Biological Problems RAS, 142290, Institutskaya st., 2, Pushchino, Russia
}

Tel: 7-496-773-2448Ｅmail: vetoshkina_d@mail.ru

Borisova-Mubarakshina M. M.

Institute of Basic Biological Problems RAS, 142290, Institutskaya st., 2, Pushchino, Russia

Tel: 7-496-773-2448Ｅmail: mubarakshinamm@gmail.com

Naydov I. A.

Institute of Basic Biological Problems RAS, 142290, Institutskaya st., 2, Pushchino, Russia Tel: 7-496-773-2448Ｅmail: eliotfur@gmail.com

Kozuleva M. A.

Institute of Basic Biological Problems RAS, 142290, Institutskaya st., 2, Pushchino, Russia

Tel: 7-496-773-2448Ｅmail: kozuleva@gmail.com

Ivanov B. N. (Corresponding author)

Institute of Basic Biological Problems RAS, 142290, Institutskaya st., 2, Pushchino, Russia Tel: 7-496-773-2448Ｅmail: ivboni@rambler.ru

Received: January 21, 2015 Accepted: February 9, 2015

doi:10.5296/jbls.v6i2.7277 URL: http://dx.doi.org/10.5296/jbls.v6i2.7277 


\section{Abstract}

In this study we describe the mechanisms of reactive oxygen species (ROS) production in the photosynthetic electron transport chain of higher plants chloroplasts under illumination. We implement an improved method for the measurement of hydrogen peroxide $\left(\mathrm{H}_{2} \mathrm{O}_{2}\right)$ production in lipid phase of photosynthetic membranes of chloroplasts. Total rate of $\mathrm{H}_{2} \mathrm{O}_{2}$ production and the production within the thylakoid membrane under operation of photosynthetic electron transport chain is evaluated. Obtained data show that even in the presence of an efficient electron acceptor, methyl viologen, an increase in light intensity leads to an increase in $\mathrm{H}_{2} \mathrm{O}_{2}$ production mainly within the thylakoid membranes. The role of $\mathrm{H}_{2} \mathrm{O}_{2}$ produced within the photosynthetic biological membrane is discussed.

Keywords: Higher plants, Photosynthesis, Thylakoid membrane, Light intensity, Hydrogen peroxide

\section{Introduction}

Biological membranes are the inherent structures of living cells since a lot of biochemical processes proceed with the membrane components involvement. Such vital assemblies as a respiratory electron-transport chain and a photosynthetic electron-transport chain are embedded into membranes of different organelles. In higher plants the primary reactions of photosynthesis occur in the thylakoid membranes of chloroplasts and are catalyzed by pigment-protein complexes of the photosynthetic electron-transport chain: photosystem II (PSII) and photosystem I (PSI). Pigments of photosystems capture and transfer light energy to the primary electron donors of the PSII and PSI reaction centers for subsequent photochemical reactions. PSII and PSI are surrounded by the light-harvesting antenna complexes. The electron flow between PS II and PSI is mediated by the plastoquinone pool, cytochrome $b_{6} / f$-complex and plastocyanin.

During photosynthesis molecular oxygen $\left(\mathrm{O}_{2}\right.$, dioxygen $)$ is evolved in water oxidizing complex associated with PSII. However, the photosynthetic electron transport chain components are also known to reduce the molecular oxygen. As a result of the reduction of $\mathrm{O}_{2}$ molecules, reactive oxygen species (ROS) are formed. The primary product of dioxygen reduction is superoxide radical, $\mathrm{O}_{2}{ }^{--}$, which is reduced to hydrogen peroxide via various pathways. In aqueous part of chloroplasts (stroma) two superoxide radicals produce hydrogen peroxide via reaction of dismutation catalyzed by superoxide dismutase.

Chloroplasts are one of the main sources of ROS in plants when exposed to light (Mubarakshina et al., 2010). It was previously found that an increase in light intensities results in an increase in both superoxide radical and hydrogen peroxide $\left(\mathrm{H}_{2} \mathrm{O}_{2}\right)$ production by the photosynthetic electron-transport chain (Ivanov et al., 2012). It has been discovered that the total increase in $\mathrm{O}_{2}{ }^{--}$and $\mathrm{H}_{2} \mathrm{O}_{2}$ production resulted from the increase in the processes within the thylakoid membrane, where the electron-transport chain components are located rather than in stroma (Mubarakshina et al., 2006). In particular, the direct evidence about the hydrogen peroxide production within the thylakoid membrane has been provided in (Borisova-Mubarakshina et al., 2012). Production of superoxide radical within the membrane 
has recently been proved in (Kozuleva et al., 2011; Kozuleva et al., 2014). The membrane superoxide radical, as stated, is converted into $\mathrm{H}_{2} \mathrm{O}_{2}$ via the reaction with plastohydroquinone, reduced plastoquinone (Mubarakshina et al., 2006; Mubarakshina, Ivanov, 2010). This reaction can be considered as a neutralization of superoxide radical, the protonated form of which, perhydroxyl radical, is known to be a strong oxidizing molecule leading to lipid peroxidation of the membrane (Møller et al., 2007).

The production of hydrogen peroxide within the thylakoid membrane was previously shown using isolated thylakoids when oxygen was the only acceptor of electrons from the photosynthetic electron-transport chain. In this context, the aim of the present work is to study the possible production of hydrogen peroxide within the membrane in the presence of an efficient electron acceptor methyl viologen that simulates the physiologically relevant conditions in term of electron transport rate. Moreover, the effect of light intensity on the $\mathrm{H}_{2} \mathrm{O}_{2}$ formation within the thylakoid lipid bilayer phase has been evaluated.

\section{Methodology}

\subsection{Isolation of Thylakoids}

Thylakoids were isolated from the 10-14 old leaves of pea plants grown in a greenhouse under natural light, as described in (Mubarakshina et al., 2006). Chlorophyll content was determined in $95 \%$ ethanol extract according to (Lichtenthaler, 1987).

\subsection{Measurement of Cytochrome C Reduction Rate and the Rate of Oxygen Concentration Changing in the Thylakoid Suspension}

Reduction of cytochrome $c$ (cyt $c$ ) by thylakoids was measured as an increase in absorbance at $550 \mathrm{~nm}$ with a reference at $540 \mathrm{~nm}$, using a dual-wavelength spectrophotometer (Hitachi 557, Japan). The photomultiplier was shielded from actinic light with a blue-green filter SZS-22 (Russia). Differential molar extinction coefficient of ferri-/ferro-cyt $c$ used was $19 \mathrm{mM}^{-1} \mathrm{~cm}^{-1}$ (Davis and San Pietro, 1977). Superoxide-dependent rate of reduction of cyt $c$ was calculated as the difference between the rate of reduction of cyt $c$ in the absence of SOD (superoxide dismutase - a water-soluble enzyme that catalyzes the dismutation reaction of superoxide radicals to $\mathrm{H}_{2} \mathrm{O}_{2}$ and $\mathrm{O}_{2}$ ) and the rate of reduction of cyt $c$ in the presence of SOD. The rate of oxygen evolution/uptake was measured in a thermostatic glass cell with a volume of $0.3 \mathrm{~mL}$ at $21^{\circ} \mathrm{C}$ using Clark-type $\mathrm{pO}_{2}$-electrode connected to the computer via ADC. The reaction mixtures in both the $\mathrm{pO}_{2}$-electrode vessel and the spectrophotometric cuvette were illuminated with red light. Light intensity was varied using neutral filters and was measured as photon flux density, $\mu$ mol quanta $\mathrm{m}^{-2} \mathrm{~s}^{-1}$, using a Li-Cor quantum meter. The source of light for the $\mathrm{pO}_{2}$-electrode vessel was red LED (Epistar, $660 \mathrm{~nm}$ ), and light from halogen lamp for the spectrophotometric cuvette was transmitted through a red cut-off filter $(\lambda>620 \mathrm{~nm})$. The basic reaction mixture contained $0.4 \mathrm{M}$ sucrose, $20 \mathrm{mM} \mathrm{NaCl}, 5 \mathrm{mM} \mathrm{MgCl}_{2}, 50 \mathrm{mM}$ HEPES-KOH (pH 7.6), and thylakoids corresponding to $10 \mu \mathrm{g} \mathrm{Chl} \mathrm{(mL)})^{-1}$. 


\section{Ml Macrothink}

\section{Results and Discussion}

\subsection{The Influence of MV on the Electron Transport Rate at Different Light Intensities}

As described in the Introduction, hydrogen peroxide may be produced in aqueous phase, i.e. outside the thylakoid membrane as well as within the thylakoid membrane (Mubarakshina et al., 2006). The aim of this work was to study the hydrogen peroxide production within the thylakoid membrane in the presence of an efficient electron acceptor, which can provide high electron transport rates relatively close to physiological ones. Unfortunately, it was not possible to apply ferredoxin (Fd), the native electron acceptor from PSI, since it reduces with a high efficiency (Asada et al., 1974) cytochrome $c$ (cyt $c$ ), which is used to prevent the hydrogen peroxide production in aqueous phase (see part 3.2). This circumstance does not permit to provide a saturating concentration of cyt $c$ for the prevention of hydrogen peroxide production in the presence of Fd. Therefore, another efficient electron acceptor methyl viologen (MV), which accepts electrons from $\mathrm{F}_{\mathrm{A}} / \mathrm{F}_{\mathrm{B}}$ components of PSI and transfers them to oxygen $(k=$ $8 \times 10^{8} \mathrm{M}^{-1} \mathrm{~s}^{-1}$ ), producing superoxide radicals, was used. $\mathrm{Km}(\mathrm{MV})$ is equal to $3 \mu \mathrm{M}$ (Ivanov et al., 1980). In order to reach a saturating concentration of cyt $c$ in the presence of MV, lower concentration, $1 \mu \mathrm{M}$, was used.

Molecular oxygen is evolved in water-oxidizing complex associated with PSII. When oxygen is the final acceptor, that is a case when either no additional acceptors or MV is used, the rate of oxygen uptake owing to oxygen reduction overcomes the rate of oxygen evolution in PSII. Therefore the oxygen uptake is observed. To investigate the influence of $1 \mu \mathrm{M} M V$ on the photosynthetic electron transport rate, the oxygen uptake rate was measured using thylakoid suspension. Two light intensities $25 \mu \mathrm{mol}$ quanta $\mathrm{m}^{-2} \mathrm{~s}^{-1}$ and $180 \mu \mathrm{mol}$ quanta $\mathrm{m}^{-2} \mathrm{~s}^{-1}$ of red light have been implemented.

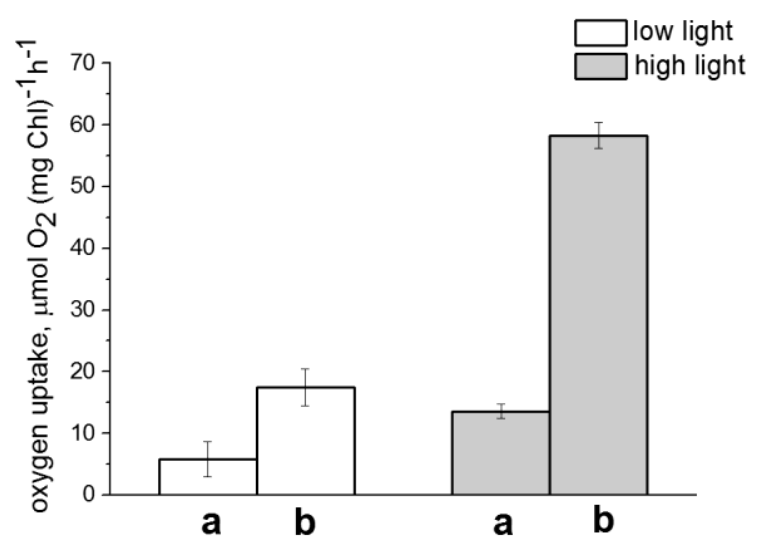

Figure 1. Effect of light intensity on the oxygen uptake rate in the absence (a) and presence (b) of $1 \mu \mathrm{M} \mathrm{MV}$. White columns - light intensity of red light $25 \mu \mathrm{mol}$ quanta $\mathrm{m}^{-2} \mathrm{~s}^{-1}$, grey columns - light intensity of red light $180 \mu \mathrm{mol}$ quanta $\mathrm{m}^{-2} \mathrm{~s}^{-1}$.

Values are presented as mean $\pm \mathrm{SE}$ of three repetitions. Three independent experiments show the same tendency.

It can be seen that the oxygen uptake rate, which reflects the total electron transport rate, 


\section{Macrothink}

increases significantly in the presence of $1 \mu \mathrm{M}$ MV (Fig. 1). Furthermore in the presence of MV the oxygen uptake rate was much higher at light intensity of $180 \mu \mathrm{mol}$ quanta $\mathrm{m}^{-2} \mathrm{~s}^{-1}$ than at $25 \mu \mathrm{mol}$ quanta $\mathrm{m}^{-2} \mathrm{~s}^{-1}$.

The rate of electron transport along photosynthetic electron-transport chain can be estimated from the rate of oxygen uptake according to known stoichiometry: $4 \mathrm{e}^{-}$per $1 \mathrm{O}_{2}$ consumed (Allen, Hall, 1973). As calculated, the electron transport rate measured in the presence of MV at $180 \mu \mathrm{mol}$ quanta $\mathrm{m}^{-2} \mathrm{~s}^{-1}$ was appr. $240 \mu$ equivalents $\mathrm{e}^{-}(\mathrm{mg} \mathrm{Chl})^{-1} \mathrm{~h}^{-1}$. This is less than the maximal physiological rates, however it is similar to that observed under some stress conditions, e.g. at limited $\mathrm{CO}_{2}$ supply due to closed stomata (Vico et al., 2013). Therefore it can be concluded that the conditions relatively close to physiological ones in term of electron transport rate can be reached using MV and high light intensity.

\subsection{Determination of the Saturating Concentration of Cyt $C$}

Formation of hydrogen peroxide within the thylakoid membrane was studied using cyt $c$, a water-soluble protein, which acts as a scavenger of superoxide radicals oxidizing them to $\mathrm{O}_{2}$. Unable to penetrate into the thylakoid membrane, cyt $c$ interacts with superoxide radicals outside the thylakoid membrane, preventing formation of hydrogen peroxide there. In order to trap all superoxide radicals produced outside the thylakoid membrane cyt $c$ should be added in sufficient amount (saturating concentration). Moreover it is important to establish the saturating concentration of cyt $c$ for superoxide-dependent reduction rate since it is known that cyt $c$ can be reduced not only by superoxide radicals, but also by components of the photosynthetic electron transport chain of thylakoids (Kruk et al., 2003). For that reason the cyt $c$ reduction rates in the absence and presence of superoxide dismutase (SOD) have been measured (Fig. 2).

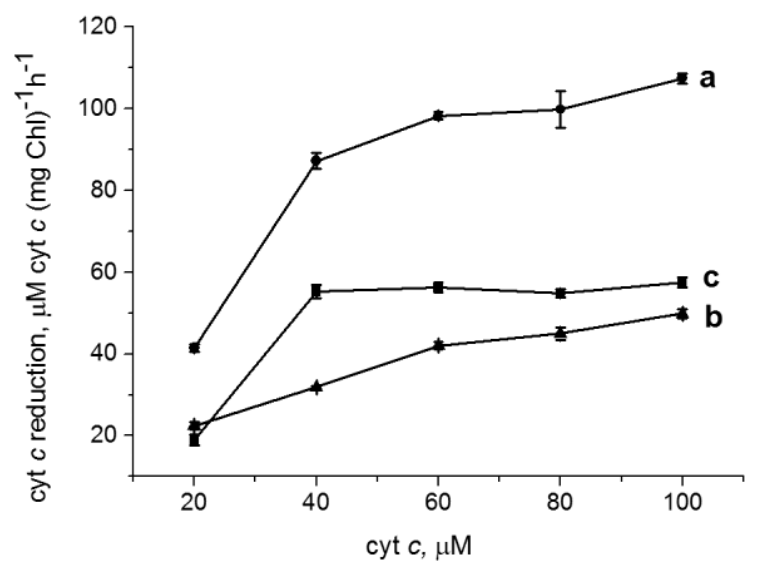

Figure 2. The dependence of cyt c reduction rate in the light on the cyt $c$ concentration.

$\mathrm{a}-\mathrm{cyt} c$ reduction rate in the absence of SOD (superoxide dismutase);

$\mathrm{b}-\mathrm{cyt} c$ reduction rate in the presence of SOD;

$\mathrm{c}$ - superoxide-dependent cyt $c$ reduction rate calculated as a difference between (a) and (b).

Light intensity $180 \mu \mathrm{mol}$ quanta $\mathrm{m}^{-2} \mathrm{~s}^{-1}$ of red light.

Values are presented as mean $\pm \mathrm{SE}$ of three repetitions. Four independent experiments show the 
same tendency.

Experiments to determine the saturating concentration for the superoxide-dependent cyt $c$ reduction rate as a difference between (a) and (b) in Fig. 2 revealed that in the presence of $1 \mu \mathrm{M}$ MV the saturation of the rate was reached at cyt $c$ concentration of $40 \mu \mathrm{M}$ (Fig. 2c). This means that at this concentration cyt $c$ scavenges all superoxide radicals produced outside the thylakoid membrane, inhibiting the production of $\mathrm{H}_{2} \mathrm{O}_{2}$ in the aqueous part. Similar concentration was found previously when no efficient electron acceptors were used (Mubarakshina et al., 2006).

\subsection{The Effect of Cyt C Addition on Oxygen Evolution Rate in the Presence of MV at Different} Light Intensities

In the presence of cyt $c$, which is both an additional non-autooxidable acceptor and an oxidant of superoxide radicals, the rate of oxygen uptake owing to oxygen reduction does not overcome the rate of oxygen evolving by the system. Therefore the addition of cyt $c$ into thylakoid suspension results in oxygen evolution instead of oxygen uptake (Fig. 3 vs Fig. 1).

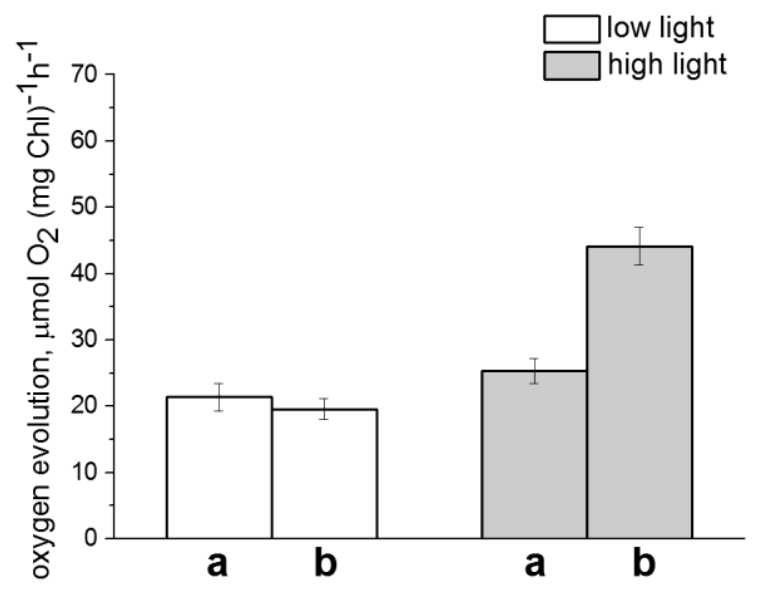

Figure 3. Effect of light intensity on the oxygen evolution rate in the absence (a) and presence (b) of $100 \mathrm{U} \mathrm{mL}^{-1}$ catalase. The reaction medium contained $1 \mu \mathrm{M} \mathrm{MV}$ and $60 \mu \mathrm{M}$ cyt c. White columns - light intensity of red light $25 \mu \mathrm{mol}$ quanta $\mathrm{m}^{-2} \mathrm{~s}^{-1}$, grey columns - light intensity of red light $180 \mu \mathrm{mol}$ quanta $\mathrm{m}^{-2} \mathrm{~s}^{-1}$.

Values are presented as mean $\pm \mathrm{SE}$ of three repetitions. Three independent experiments show the same tendency.

To answer the question, whether hydrogen peroxide is formed within the thylakoid membrane even in the presence of MV, the oxygen evolution rate in the thylakoid suspension in the absence and presence of catalase was measured using cyt $c$ at saturating concentration (Fig. 3). Catalase - an enzyme decomposing hydrogen peroxide to form molecular oxygen and water. If an additional increase in the oxygen evolution rate can be observed under these conditions when catalase is added, it indicates the formation of $\mathrm{H}_{2} \mathrm{O}_{2}$ production within the membrane since cyt $c$ prevents the formation of $\mathrm{H}_{2} \mathrm{O}_{2}$ outside the membrane.

Fig. 3 shows that at $25 \mu \mathrm{mol}$ quanta $\mathrm{m}^{-2} \mathrm{~s}^{-1}$ the addition of catalase had no effect on oxygen 
evolution. The addition of catalase at $180 \mu \mathrm{mol}$ quanta $\mathrm{m}^{-2} \mathrm{~s}^{-1}$ resulted in a noticeable increase in the oxygen evolution rate. Thus under high light conditions even in the presence of $\mathrm{MV}$, $\mathrm{H}_{2} \mathrm{O}_{2}$ is formed within the thylakoid membrane. The difference between oxygen evolution rate in the presence and absence of catalase, presented in Fig. 3, can be used to estimate the amount of $\mathrm{H}_{2} \mathrm{O}_{2}$ formed within the thylakoid membrane.

The stoichiometry of $\mathrm{H}_{2} \mathrm{O}_{2}$ decomposition by catalase gives one molecule of $\mathrm{O}_{2}$ from two molecules of $\mathrm{H}_{2} \mathrm{O}_{2}$. In high light the rate of $\mathrm{H}_{2} \mathrm{O}_{2}$ production within the thylakoid membrane is estimated to be $38 \pm 4 \mu$ moles $\mathrm{H}_{2} \mathrm{O}_{2} \mathrm{mg} \mathrm{Chl}^{-1} \mathrm{~h}^{-1}$ (Fig. 3). If the rate of $\mathrm{H}_{2} \mathrm{O}_{2}$ production in the absence of cyt $c$ in Fig. 1 (it is equal to the oxygen uptake rate multiplied by two) would be taken as $100 \%$, then it can be estimated that the fraction of $\mathrm{H}_{2} \mathrm{O}_{2}$ production within the thylakoid membrane reaches $30 \%$.

\subsection{The Pathways of Hydrogen Peroxide Formation in the Absence and Presence of MV}

In the absence of either $\mathrm{MV}$ or other acceptor, such as Fd, the terminal cofactors of PSI, $\mathrm{F}_{\mathrm{A}} / \mathrm{F}_{\mathrm{B}}$, reduce $\mathrm{O}_{2}$ to superoxide radical. $\mathrm{F}_{\mathrm{A}} / \mathrm{F}_{\mathrm{B}}$ are situated at PSI subunit PsaC, which is exposed to stroma. Together with PsaD and PsaE subunits they form a docking site for a water-soluble protein $\mathrm{Fd}$. Based on this structure, one may propose that $\mathrm{O}_{2}$ reduction by $\mathrm{F}_{\mathrm{A}} / \mathrm{F}_{\mathrm{B}}$ in the absence of $\mathrm{MV}$ leads to $\mathrm{O}_{2}{ }^{--}$appearance outside the membrane. Further these superoxide radicals are converted to $\mathrm{H}_{2} \mathrm{O}_{2}$ via dismutation reaction if cyt $c$ is absent (pathway 1 of $\mathrm{H}_{2} \mathrm{O}_{2}$ production; Figure 4A). It cannot be excluded that a small portion of $\mathrm{O}_{2}{ }^{--}$ may dismutate to $\mathrm{H}_{2} \mathrm{O}_{2}$ in the close vicinity of the thylakoid membrane surface without being trapped by cyt $c$ even if cyt $c$ is added (pathway 2 of $\mathrm{H}_{2} \mathrm{O}_{2}$ production; Figure 4A).

A

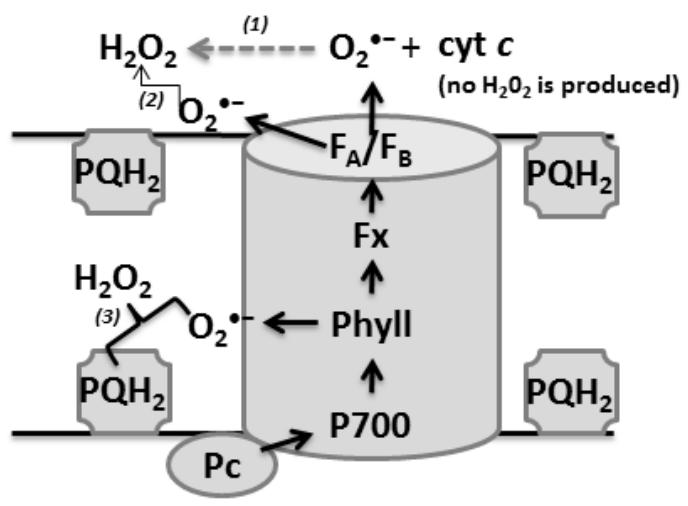

B

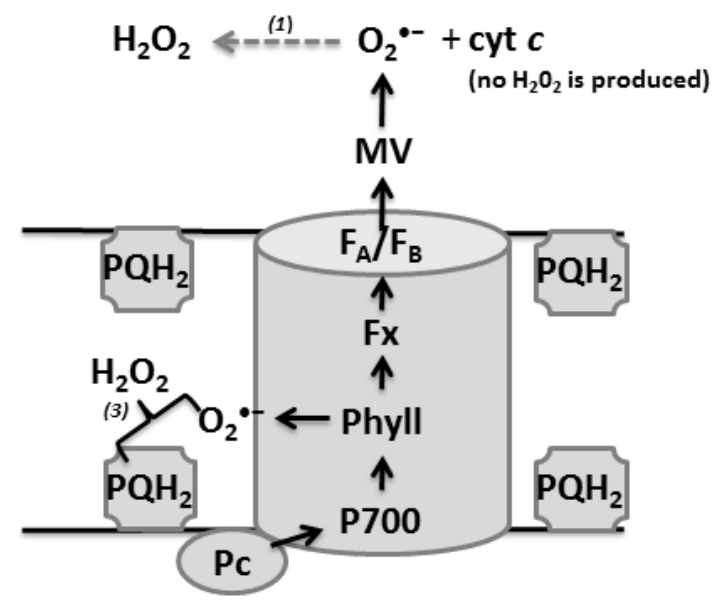

Figure 4. The tentative scheme of the electron transfer and $\mathrm{H}_{2} \mathrm{O}_{2}$ production pathways in PSI in the absence (A) and presence of MV (B). Black arrows - the electron transfer pathways.

Dashed arrows - the pathway of $\mathrm{H}_{2} \mathrm{O}_{2}$ production in the absence of cyt $c$.

P700 - reaction center of PSI; $F_{X}$, [4Fe-4S] cluster, and Phyll, phylloquinone, - intermediate cofactors of electron transfer in PSI; $\mathrm{F}_{\mathrm{A}}$ and $\mathrm{F}_{\mathrm{B}}$ - the terminal cofactors of electron transfer; PC, plastocyanin, - a donor of electrons for PSI; $\mathrm{PQH}_{2}$, plastohydroquinone. 
Another source of superoxide radicals outside the membrane could be the reaction of $\mathrm{O}_{2}$ with plastosemiquinone of the plastoquinone pool at the membrane-water interface (not shown) (Mubarakshina, Ivanov, 2010). The source of superoxide radicals detected within the membrane (Kozuleva et al., 2011) is still under debate (Kozuleva et al., 2014). Both pheophytin, the primary electron acceptor in PSII, and phylloquinone, a secondary electron acceptor in PSI, possess negative midpoint potentials that enables $\mathrm{O}_{2}$ reduction in the membrane where $\mathrm{Em}\left(\mathrm{O}_{2} / \mathrm{O}_{2}{ }^{-}\right)$is close to $-500 \div-600 \mathrm{mV}$ (Afanas'ev, 1989). Phyllosemiquinone in PSI shows a longer life-time than reduced pheophytin in PSII, thus phyllosemiquinone seems to be more probable candidate for superoxide radical production within the membrane (Em values (Phyll/Phyll ${ }^{0^{-}}$) in $\mathrm{A}_{1 \mathrm{~A}^{-}}$and $\mathrm{A}_{1 \mathrm{~B}^{-}}$sites are $-671 \div-844 \mathrm{mV}$, respectively (Ptushenko et al., 2008)). The role of phylloquinone in $\mathrm{O}_{2}$ reduction was shown recently (Kozuleva et al., 2014, see Introduction).

The pathway 3 of $\mathrm{H}_{2} \mathrm{O}_{2}$ production occurs within the thylakoid membrane via reaction of $\mathrm{O}_{2}{ }^{--}$ with plastohydroquinone, the fully reduced plastoquinone $\left(\mathrm{PQH}_{2}\right)$ (Figure $4 \mathrm{~A}, \mathrm{~B}$; see Introduction). It is worth noting that under continuous light conditions plastohydroquinone spreads along the entire membrane, and the quantity of plastohydroquinone is quite high. Therefore $\mathrm{O}_{2}{ }^{--}$produced deeply within the membrane by phyllosemiquinone has a high probability to reach the plastohydroquinone molecule.

The advantage of MV usage, except the providing the higher electron transport rate, is that the addition of MV partly or significantly diminishes the pathway 2 of $\mathrm{H}_{2} \mathrm{O}_{2}$ production. As a result, hydrogen peroxide is mainly produced within the membrane by the pathway 3 (Figure 4B). In the present study we provide data showing the hydrogen peroxide production within the thylakoid membrane in the presence of an efficient electron acceptor.

\section{Conclusion and Perspectives}

The main question that arises: what role $\mathrm{H}_{2} \mathrm{O}_{2}$ formed within the thylakoid lipid bilayer can play? We propose that the $\mathrm{H}_{2} \mathrm{O}_{2}$ may be a signal molecule, which triggers the acclamatory changes at the level of thylakoid membrane. For example, it is known that under the changes in the spectral composition of light, light-harvesting complexes of thylakoid membranes can be reorganized, this process was named "state transition". The outer part of LHCII of higher plants and green algae can migrate from PSII to PSI and back that would lead to changes in the size of both LHCII and LHCI (Aro and Ohad, 2003). Phosphorylation of LHCII proteins by kinase STN7 (Rochaix et al., 2012) leads to migration of LHCII from PSII to PSI (state 2) when light preferential to PSII is implemented. Dephosphorylation by phosphatase enzyme PPH1/TAP38 (Pribil et al., 2010; Shapiguzov et al., 2010) provides a return of LHCII from PSI to PSII (state 1) under far-red light preferential to PSI. Thus, state transition process is a short-term adaptation of the photosynthetic apparatus to changes in light conditions, which allows redistribution of the excitation energy between two photosystems.

A key role in the initiation of state transition is attributed to the redox state of the plastoquinone pool (Allen et al., 1981). However, the molecular carrier of the signal that mediates the connection of plastoquinone pool and state transition initiation is still unknown. Since hydrogen peroxide is produced within the thylakoid membrane with the plastoquinone pool 
components involvement (see introduction), we propose that $\mathrm{H}_{2} \mathrm{O}_{2}$ can be the signal. Being produced within the membrane, $\mathrm{H}_{2} \mathrm{O}_{2}$ can diffuse into the lumen (inside thylakoid space) and oxidizes cysteine residues of STN7 kinase converting the enzyme to an active state thus initiating state transition. At present the investigation of $\mathrm{H}_{2} \mathrm{O}_{2}$ on state transition process as well as on the redox state of STN7 kinase is in progress.

Another open question that still exists is the estimation of input of the $\mathrm{H}_{2} \mathrm{O}_{2}$ produced within the thylakoid membrane into the total $\mathrm{H}_{2} \mathrm{O}_{2}$ production by chloroplasts in the presence of native electron acceptors.

\section{References}

Mubarakshina, M. M., Ivanov, B. N., Naydov, I. A., Hillier, W., Badger, M. R., \& Krieger-Liszkay A. (2010). Production and diffusion of chloroplastic $\mathrm{H}_{2} \mathrm{O}_{2}$ and its implication to signalling. Journal of experimental botany. 61(13). 3577-3587. http://doi.org/10.1093/jxb/erq171

Ivanov, B., Kozuleva, M., Mubarakshina, M. (2012) Oxygen metabolism in chloroplast. In: Cell Metabolism - Cell Homeostasis and Stress Response (Bubulya P. ed.) - InTech (www.intechopen.com). 39-72.

Mubarakshina, M., Khorobrykh, S., \& Ivanov, B. (2006). Oxygen reduction in chloroplast thylakoids results in production of hydrogen peroxide inside the membrane. Biochimica et Biophysica Acta. 1757(11). 1496-1503. http://doi.org/10.1016/j.bbabio.2006.09.004

Borisova (Mubarakshina), M. M., Kozuleva, M. A., Rudenko, N. N., Naydov, I. A., Klenina, I. B., \& Ivanov B. N. (2012). Photosynthetic electron flow to oxygen and diffusion of hydrogen peroxide through the chloroplast envelope via aquaporins. Biochimica et Biophysica Acta (BBA)-Bioenergetics. 1817(8). 1314-1321. http://doi.org/10.1016/j.bbabio.2012.02.036

Kozuleva, M., Klenina, I., Proskuryakov, I., Kirilyuk, I., \& Ivanov, B. (2011). Production of superoxide in chloroplast thylakoid membranes: ESR study with cyclic hydroxylamines of $\begin{array}{llll}\text { different lipophilicity. } & \text { FEBS } & \text { letters. } & \text { 585(7). }\end{array}$ http://doi.org/10.1016/j.febslet.2011.03.004

Kozuleva, M. A., Petrova, A. A., Mamedov, M. D., Semenov, A. Y., \& Ivanov B. N. (2014). O 2 reduction by photosystem I involves phylloquinone under steady-state illumination. FEBS letters. 588(23). 4364-4368. http://doi.org/10.1016/j.febslet.2014.10.003

Mubarakshina, M. M., \& Ivanov, B. N. (2010). The production and scavenging of reactive oxygen species in the plastoquinone pool of chloroplast thylakoid membranes. Physiologia plantarum. 140(2). 103-110. http://doi.org/10.1111/j.1399-3054.2010.01391.x

Møller, I. M., Jensen, P. E., \& Hansson, A (2007) Oxidative modifications to cellular components in plants. Annual Review of Plant Biology. 58. 459-481. http://doi.org/10.1146/annurev.arplant.58.032806.103946

Lichtenthaler, H. K. (1987). Chlorophylls and carotenoids: pigments of photosynthetic $\begin{array}{lllll}\text { biomembranes. } & \text { Methods } & \text { of } & \text { 350-382. }\end{array}$ http://doi.org/10.1016/0076-6879(87)48036-1 
Davis, D. J., \& Pietro, A. S. (1977). Interactions between spinach ferredoxin and other electron carriers: The involvement of a ferredoxin: Cytochrome $c$ complex in the ferredoxin-linked cytochrome $\mathrm{c}$ reductase activity of ferredoxin: NADP+ oxidoreductase. Archives of biochemistry and biophysics. 182(1). 266-272. http://doi.org/10.1016/0003-9861(77)90307-1

Asada, K., Kiso, K. \& Yoshikawa K. (1974). Univalent Reduction of Molecular Oxygen by Spinach Chloroplasts on Illumination. The Journal of Biological Chemistry. 249(7). 2175-2181.

Ivanov, B. N., Red'ko, T. P., Shmeleva, V. L. \& Mukhin, E. N. (1980). The role of ferredoxin in pseudocyclic electron transport in isolated pea chloroplasts. Biochemistry (Moscow). 45(8). $1425-1432$

Allen, J. F. \& Hall, D. O. (1973). Superoxide reduction as a mechanism of ascorbate-stimulated oxygen-uptake by isolated chloroplasts. Biochemical and Biophysical Research Communications. 52(3). 856-862. http://doi.org/10.1016/0006-291X(73)91016-4

Vico, G., Manzoni, S., Palmroth, S., Weih, M., Katul, G. (2013). A perspective on optimal leaf stomatal conductance under $\mathrm{CO}_{2}$ and light co-limitations. Agricultural and Forest Meteorology. 12. 191-199. DOI: 10.1016/j.agrformet.2013.07.005

Kruk, J., Jemiola-Rzeminska, M., Strzalka, K. (2003) Cytochrome $c$ is reduced mainly by plastoquinol and not by superoxide in thylakoid membranes at low and medium light intensities: its specific interaction with thylakoid membrane lipids. Biochemical Journal. 375(2). 215-220. http://doi.org/10.1042/BJ20021820

Afanas'ev, I. B. (1989). Superoxide Ion: Chemistry and Biological Implications. CRC Press. Boca Raton. Florida.

Ptushenko, V. V., Cherepanov, D. A., Krishtalik, L. I., \& Semenov, A. Y. (2008). Semi-continuum electrostatic calculations of redox potentials in photosystem I. Photosynthesis Research. 97, 55-74. DOI 10.1007/s11120-008-9309-y

Aro, E. M., \& Ohad, I. (2003). Redox regulation of thylakoid protein phosphorylation. Antioxidants and Redox Signaling, 5(1), 55-67. http://doi.org/10.1089/152308603321223540

Rochaix, J. D., Lemeille, S., Shapiguzov, A., Samol, I., Fucile, G., Willig, A., \& Goldschmidt-Clermont M. (2012). Protein kinases and phosphatases involved in the acclimation of the photosynthetic apparatus to a changing light environment. Philosophical Transactions of the Royal Society B: Biological Sciences. 367(1608). 3466-3474. http://doi.org/10.1089/ars.2012.5110

Pribil, M., Pesaresi, P., Hertle, A., Barbato, R., \& Leister D. (2010). Role of plastid protein phosphatase TAP38 in LHCII dephosphorylation and thylakoid electron flow. PLoS biology. 8(1). http://doi.org/10.1371/journal.pbio.1000288

Shapiguzov, A., Ingelsson, B., Samol, I., Andres, C., Kessler, F., Rochaix, J. D., \& Goldschmidt-Clermont M. (2010). The PPH1 phosphatase is specifically involved in LHCII 
dephosphorylation and state transitions in Arabidopsis. Proceedings of the National Academy of Sciences. 107(10). 4782-4787. http://doi.org/10.1073/pnas.0913810107

Allen, J. F., \& Pfannschmidt, T. (2000). Balancing the two photosystems: photosynthetic electron transfer governs transcription of reaction centre genes in chloroplasts. Philosophical Transactions of the Royal Society of London. Series B: Biological Sciences. 355(1402). 1351-1359. http://doi.org/10.1098/rstb.2000.0697

\section{Copyright Disclaimer}

Copyright for this article is retained by the author(s), with first publication rights granted to the journal.

This is an open-access article distributed under the terms and conditions of the Creative Commons Attribution license (http://creativecommons.org/licenses/by/3.0/). 